\title{
Preliminary Evaluation of a Pressure Clinic in a New Spinal Injuries Unit
}

\author{
F. A. Rothery, SRN, RSCN \\ Duke of Cornwall Spinal Treatment Centre, Odstock Hospital, Salisbury, \\ Wiltshire, SP2 8BF, UK.
}

\section{Summary}

A pressure clinic is described, and its effectiveness in preventing pressure sores assessed. Preliminary results suggest that the incidence of pressure sores can easily be reduced by the introduction of this service.

Key words: Pressure clinic; Pressure sores.

It is well known that patients with spinal cord injury have a high incidence of pressure sores. Coghlan et al. (1977) showed that of paraplegic patients treated at the G.F. Strong Rehabilitation Centre in Canada and discharged before 1976, $46 \%$ who responded to a questionnaire had had at least one major pressure sore, and at least $30^{\circ}$ o a less severe breakdown. Lawes (1984) found that of patients discharged from two British spinal units, between 1975 and $1981,15^{\circ}{ }_{0}$ were readmitted to hospital with pressure sores, and a further $25^{\circ}{ }_{0}$ had suffered one or more sores but had not been readmitted.

The prevention of pressure sores was therefore made a primary objective in patient management at The Duke of Cornwall Spinal Treatment Centre right from its inception in 1984. The importance of evaluation is emphasised in four ways. 1) The ethos of the unit is one of patients taking responsibility for their own care and well-being, including the avoidance of pressure problems. The importance of this is reinforced by all staff in the multidisciplinary team. 2) A pressure clinic has been established, every patient attending as part of his or her rehabilitation programme and at each outpatient follow-up. 3) A comprehensive education programme ensures that the patient fully understands the causes, prevention, and implications of pressure sores. 4) A community liaison nurse visits patients at home after discharge, giving advice and support.

Pressure clinics for the prevention of pressure sores in spinal cord injury patients have been described by Rodgers (1973) Manley (1977) and FergusonPell et al. (1980). The Royal Perth Rehabilitation Hospital (Noble, 1981) achieved a $53 \%$ reduction in the annual number of admissions for pressure sores following the introduction of a pressure clinic. 
As pressure sores are primarily caused by social and psychological rather than medical factors (Lawes, 1984), the Duke of Cornwall Spinal Treatment Centre pressure clinic attempts to evaluate the quality of life of each patient.

\section{The pressure clinic}

The day to day running of the clinic is under the care of a Nursing Sister assisted by a therapy helper. A physiotherapist, occupational therapist and community liaison nurse all contribute expertise, information and advice.

Inpatients are seen at the clinic as soon as the initial period of bed rest has ended and they are first up in a wheelchair. They are seen twice monthly, more often if necessary, and again before discharge. Patients are responsible for making and keeping their appointments. Each patient is encouraged to explore and discuss all aspects of his or her physical and mental well-being. Outpatients are seen at each medical follow-up.

The objectives of the clinic are: 1) To assess and advise the patient with regard to posture, comfort, wheelchair cushion and other aspects of pressure prevention. 2) To assess each patient's susceptibility to pressure sores, considering quality of life, home environment, diet, attitude to self-care, and level of motivation. 3) To link with the community liaison nurse, referring patients to her who appear to be 'at risk' or who have problems at home. 4) To reinforce patient education in pressure prevention and pressure awareness. 5) To collect data for future research.

Interface pressures between the cushion and the ischial tuberosities are measured using the Talley Skin Pressure Evaluator (Fig. 1). Most patients have satisfactory pressure readings on a 4 inch pincore latex cushion available from the Department of Health and Social Security (DHSS). For patients able to relieve their own pressures, but who have high pressure measurements on a pincore latex cushion, we make an ischial cut-out cushion in the pressure clinic

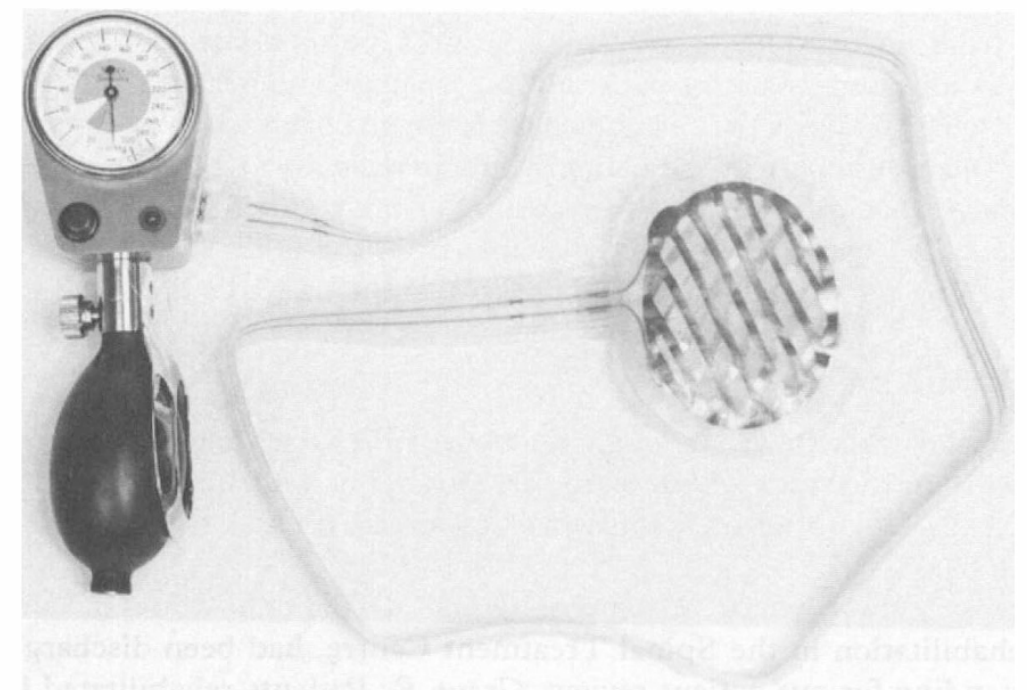

Figure 1 Talley Skin Pressure Evaluator. 


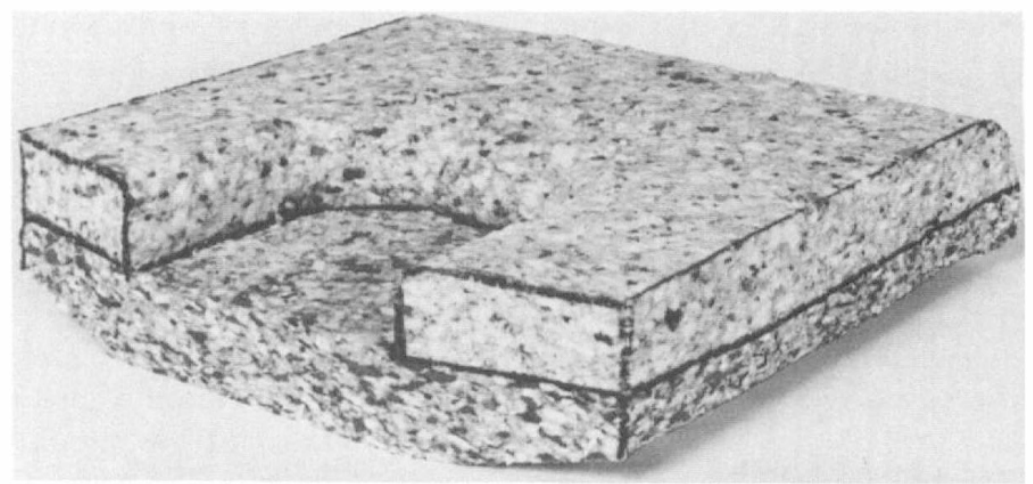

Figure 2 Ischial cut-out cushion made in the Pressure Clinic.

as follows: A 2 inch thick piece of $4 \mathrm{lb}$ bonded foam is glued on to a 2 inch thick piece of $6 \mathrm{lb}$ bonded foam. The cushion is shaped at the back and the base, to fit the sag of the wheelchair canvas, and is sloped to direct pressure away from the ischial tuberosities. The patient's ischial tuberosities are measured to determine the width and length of the cut-out. The depth of the cut-out will depend on pressure measurements under the ischial tuberosities (Fig. 2).

Cutting foam away from the ischial areas invariably increases pressure on the trochanters, which usually makes this type of cushion unsuitable for patients who cannot relieve pressure. Several proprietary cushions are available on which patients can be tested. Tetraplegic patients often require a Roho cushion.

Patients are encouraged to contact the clinic if they have any problems regarding pressure.

In choosing the most suitable wheelchair cushion, a number of questions need to be asked: 1) What is the safe level of pressure over the ischial tuberosities? A reading of $60 \mathrm{~mm} \mathrm{Hg}$ is considered a safe limit for patients who can relieve their own pressure by pushing up on the arms or wheels of the chair, by leaning from side to side, or by leaning forward, chin on knees. A reading of 35 $\mathrm{mm} \mathrm{Hg}$ is considered safe for patients who are unable to perform pressure relief for themselves. 2) Does the cushion cause erythema over the bony prominences? 3) Does the cushion affect the patient's independence? Some cushions, e.g. the Roho, may cause difficulties with transfers or are too heavy for the patient to handle, e.g. gel cushions. 4) Is it available from the DHSS, or if not, can the patient afford it? 5) Is it robust enough to suit the patient's lifestyle?

\section{Patients and methods}

Patients who walked well enough not to require a wheelchair indoors were excluded from the study. A pressure sore was defined as an area of reddened or damaged tissue, caused or made worse by pressure, and taking more than 2 weeks to heal.

There were two groups of patients Group $A$ : Patients who had completed their rehabilitation in the Spinal Treatment Centre, had been discharged, and were attending for out patient review. Group B: Patients rehabilitated in other hospitals who were attending the Spinal Treatment Centre for the first time. 
Records of all patients seen at the pressure clinic between 09.01.84 and 09.01.86 were examined. Patients from Group A were normally seen 6 weeks after discharge, then 6 monthly for 1 year, and then yearly.

Patients who did not attend for their outpatient appointments were referred to the community liaison nurse who then visited them at home. Patients with pressure problems were referred back to the pressure clinic.

In the pressure clinic records were kept of all admissions to the unit, and these were studied to identify the patients admitted with pressure sores.

\section{Results}

Group $A$ : Fifty patients. Only 1 patient was readmitted to the unit with pressure sores-a man, aged 22, with a complete tetraplegia below C5. He developed bruised areas over his posterior iliac crests, which took 6 weeks to resolve, although the skin remained intact. One other patient developed pressure sores, a 73-year-old lady, also with a complete tetraplegia below C5, who developed multiple sores while in a geriatric hospital a few weeks before her death. Of this group therefore $4^{\circ}{ }_{0}$ developed pressure sores.

Group B: Ninety eight patients. Sixty $\left(61_{0}^{\circ}\right)$ reported that they had had at least one pressure sore in the past. Five patients $\left(5^{\circ}{ }_{0}\right)$ required admission for treatment of sores which developed after attending the pressure clinic.

Eighteen patients from Group B were admitted to this unit for treatment of pressure sores. All have been discharged and have developed no further sores.

\section{Discussion}

Two years is not sufficiently long to fully assess the effectiveness of the pressure clinic. However, the results so far are encouraging when compared with the observations of Thiyagarajan and Silver (1984). They found that $19(25 \%)$ out of 75 patients admitted with pressure sores had developed them within 1 year of their initial discharge from hospital. They also noted that patients who had had one pressure sore, tended to develop further sores; in fact $33\left(44^{\circ}\right)$ of their 75 patients admitted had recurrent sores. No patient admitted to this unit with sores has had a further sore.

The pressure clinic is not the only method of pressure sore prevention in this unit. The educational programme, the commitment of staff, and the continuing support of the community liaison nurse are all contributory factors; however the existence of a pressure clinic emphasises the importance given to prevention of pressure sores and therefore serves to motivate patients to accept responsibility for this aspect of their lives. This facility should be available in every spinal injuries unit.

The continued collection of data from both inpatients and out patients should clarify the factors which make some patients more susceptible than others to pressure sores and this will obviously enhance the effectiveness of the pressure clinic. A longer follow-up is planned, in order to fully appreciate its use in the long term prevention of pressure sores. If the long term incidence of sores remains low, it will give strength to our belief that pressure sores are truly preventable. 


\section{Acknowledgements}

This paper was originally presented to the Society for Tissue Viability in April 1986 and awarded the Bayer Prize. The Society has kindly made it available for publication. I wish to thank Mr David Grundy for his help in preparing this manuscript.

\section{References}

Coghlan JK, Robinson CE, Newmarch B, Jackson G 1977 Paraplegia-A Follow-up Functional Review. British Columbia Medical fournal 19:386-389.

Lawes CJ 1984 Pressure Sore Readmission for Spinal Injured People. Care, Science and Practice 4:2,4-8.

Rogers JE 1973 Tissue Trauma Group-Annual Report of Progress; Task No. 5; 16, Rehabilitation Centre at Rancho Los Amigos Hospital. (December, 1972-November 1973).

Manley MT, Wakefield E, Key AG 1977 The Prevention and Treatment of Pressure sores in the Sitting Paraplegic. South African Medical fournal 29:771-774.

Ferguson-Pell MW, Wilkie IC, Reswick JB, Barbenel JC 1980 Pressure Sore Prevention for the Wheelchair-Bound Spinal Injury Patient. Paraplegia 18:42-51.

Noble PC 1981 The Prevention of Pressure Sores in Persons with Spinal Cord Injuries.

Monograph 11. International Exchange of Information in Rehabilitation, World Rehabilitation Fund, Inc., 400 East 34th Street, New York 10016.

Thiyagarajan C, Silver JR 1984 Aetiology of Pressure Sores in Patients with Spinal Cord Injury. British Medical fournal 289:1487-1490. 